А. О. Зуєв

Національний технічний університет «Харківський політехнічний інститут», Харків

\title{
РОЗРОБКА МЕТОДУ КОМПАКТНОГО ЗБЕРІГАННЯ ПОЛІВ ВИСОТ У ГІС ТА ІМІТАЦІЙНО-ТРЕНАЖЕРНИХ КОМПЛЕКСАХ БПЛА
}

\begin{abstract}
Метою статті є розробка та дослідження методу компактного зберігання полів висот описують реальні ландшафти, які використовуються в ГІС та імітаційно-тренажерних комплексах. Визначено величини необхідної дискретизації поля для імітаційно-тренажерного комплексу. Розглянуто метод блочного кодування і декодування поля висот, який дозволяє обробляти як поодинокі, так і групові запити висот без повного декодування поля. Запропоновано практичну реалізацію алгоритму побудови безлічі векторів, які кодують поле з мінімальною похибкою. При проведенні дослідження шляхів мінімізації похибки кодування, використовувалися методи кластерного аналізу. Використання запропонованих методів дозволяє створити програмне забезпечення як для бортового комп'ютера ГІС БПЛА і наземної станції управління, так і для імітаційно-тренажерного комплексу що може бути використаний для підготовки операторів і попереднього моделювання польотного завдання в реальному масштабі часу. Проведено аналіз розподілу похибки кодування полів, наведено розподіл величин похибки по площі поля для різних типів ландшафтів. Показано швидкодію функції запиту висот для різних типів реальних ландшафтів, модель яких була синтезована за даними радіолокаційного сканування Землі.
\end{abstract}

Ключові слова: ГІС, імітаційно-тренажерні комплекси, БПЛА, поля висот, кодування даних, ландшафти, кластерний аналіз.

\section{Вступ}

Поля висот широко застосовуються як в ГІС так і в імітаційно-тренажерних комплексах, так як мають ряд переваг: однакове представлення усіх ділянок ландшафту, вони можуть бути отримані як результат радіолокаційного або лідарного сканування. Зберігання висот у вигляді рівномірного масиву (поля) висот дозволяе максимально прискорити процес обчислення висоти в заданій точці. Але таке представлення має також очевидний недолік - квадратичну залежність обсягу пам'яті, яка необхідна для зберігання поля, від його розмірів в горизонтальній площині. Зменшити обсяг пам'яті необхідної для зберігання поля можна, наприклад зменшивши дискретизацію, але це веде до значної втрати точності передачі контурів ландшафту, зникнення дрібних деталей, появі різноманітних артефактів.

Аналіз літературних даних i постановка проблеми В роботі [1] розглянуто метод реконструювання полів висот за допомогою фракталів. Такий тип реконструювання дозволяє значно скоротити обсяг даних що описують поле (більш ніж у 10 разів), але придатен для реконструювання таких ландшафтів, що натурально мають фрактальну структуру. Це утруднює або унеможливлює реконструкцію ландшафтів які мають багато артефактів, саме такі що необхідні для імітаційно-тренажерного комплексу БПЛА який застосовується для моніторингу об'єктів електроенергетики.

В [2] наведено метод інтерактивного редагування ландшафту стисненого за допомогою вейвлетів. В статі розглянуто стиснення як для даних що описують висоти ландшафту, так і кольорової компоненти поверхні ландшафту. Опис ландшафту розділяється на високочастотну так низькочастотну частини, які кодуються незалежно за допомогою DWT перетворення, після чого проводиться стиснення методом Хафману реалізованим на GPU. На- ведений метод в першу чергу призначений для кодування колірної складової і мінімізації операцій обміну даними між GPU і CPU в процесі редагування. А для полів висот не наведено величин одержуваних похибок кодування.

Автори у [3] наводять метод стиснення полів висот в якому декомпресія досягається за допомогою кривих Безье на які накладається корегуючий шар даних. Цей метод дозволяє декодувати висоті для окремих точок ландшафту, та може бути реалізований на GPU або CPU.

Метод може кодувати поля висот 3 втратами i без втрат. Максимальна абсолютна похибка становить 2 м, а середня менш ніж 0,4 м. Але даний метод обчислювально-складний (потребує близько 80 операцій $з$ плаваючою комою та 20 цілочисельних операцій). Для цього методу потрібно щоб поверхня поля висот була досить гладкою, інакше апроксимація у вигляді кривих Безье буде давати значну похибку і буде потрібен великий обсяг коригувальних даних, що призведе до зниження величини стиснення поля. Адаптивна декомпресія, яка використовується в даному методі $є$ надмірною для моделювання нізьковисотних польотів БПЛА.

В [4] розглянуто метод 3 лінійним передбаченням та стиснення бітового потоку за допомогою RBUC коду. При цьому кожна частка ландшафту декодується послідовно за допомогою геометричної мікропрограми. Але цей метод не дозволяє декодувати окремі точки поля висот. Інший підхід до стиснення полів висот запропоновано в [5], він базується на загальновідомому алгоритмі стиснення LZ77. Метод реалізовано за допомогою API CUDA, але недоліком такого методу є те що він працює в одномірному просторі, і не може виконувати запити висот у полі, без його повного декодування.

Метод WAH, та його реалізація на GPU, наведений в [6] застосовує растрове розширення та стиснення. Але цей метод не бере до уваги просторовий 
аспект ландшафтних даних, та для обробки запиту висот потрібна повна декомпресія поля. Ще один метод [7], який базується на застосуванні R-дерев, може бути застосовано для стиснення полів висот. Авторами наведено оптимальну реалізацію R-дерев, за допомогою лінійного масиву, що забезпечує ефективну передачу даних. Але як і у попередніх методах не розглядається проблема стиснення та адресації двомірних масивів даних.

Таким чином можна зазначити що значним недоліком майже всіх розглянутих методів $є$ відсутність можливості індивідуального запиту висоти, який $є$ одним 3 ключових моментів у функціонуванні різноманітних підсистем імітаційно-тренажерного комплексу БПЛА або ГІС.

В статі розглядається вдосконалений метод [8], стиснення полів висот, який може бути застосовано як в імітаційно-тренажерних комплексах різноманітного напряму, так і у ГІС та навігаційних системах, як джерело даних що описують поверхню ландшафту.

Метою статті $є$ розробка і дослідження методу стиснення та компактного зберігання полів висот, цифрові моделі яких отримано за результатами сканування земної поверхні. Метод також повинен забезпечувати обробку групових та поодиноких запитів висот, забезпечуючи швидкодію порівняну 3 аналогічними запитами з некодованого поля.

\section{Результати досліджень}

1. Метод стиснення полів висот. Потрібна величина дискретизації поля значно залежить від перепаду висот. При величині дискретизації по вертикалі менше за 5 см помітних візуальних артефактів на ландшафті не спостерігається. Вважаючи, що діапазон висот ландшафтів, притаманних для рівнинній та пагористої місцевості становить менше ніж $\Delta H=100$, кількість рівнів $N$, яка необхідна для зберігання висоти 3 дискретизацією $d=0,05 \mathrm{~m}$ становитиме 2000. А кількість біт необхідних для такого представлення висоти становить 11 .

Загальною властивістю полів висот які описують реальні ландшафти, є відносна плавність зміни висоти, але варто врахувати, що штучні споруди, різні інженерні спорудження можуть вносити різкі перепади до структури поля.

Таким чином для моделювання дрібних деталей ландшафту необхідна дискретизація, не більш ніж $0,5 \mathrm{M}$.

Для кодування все поле висот розбивається на блоки розміром $4 \times 4$ висоти, таким чином кожен блок складається з 16 висот - множина $h_{i}$ i кодується незалежно від інших, за допомогою наступного алгоритму:

1) Визначається мінімальна і максимальна висоти в блоці:

$$
\begin{aligned}
& h_{\min }=\min \left(h_{0}, h_{1}, \ldots, h_{15}\right) ; \\
& h_{\max }=\max \left(h_{0}, h_{1}, \ldots, h_{15}\right) .
\end{aligned}
$$

2. Розраховуються чотири опірні висоти для кодування блоку $h_{i}^{c}$.
3. Для кожної $h_{i}$ вибирається відповідна їй висота кодування $h_{j}^{c}$ така, що дає мінімальну помилку при заміні:

$$
\left|h_{i}-h_{j}^{c}\right| \rightarrow \min
$$

4. Формується блок кодів висот. Для чого використовується двобітний код, відповідно для опорних висот коди є наступними:

$$
\begin{aligned}
& h_{0}^{c}=\{00\}, h_{1}^{c}=\{01\}, \\
& h_{2}^{c}=\{10\}, h_{3}^{c}=\{11\} .
\end{aligned}
$$

5. Синтезується стиснений блок, що складається 3 двох опорних висот $h_{0}^{c}$ i $h_{3}^{c}$, і блоку кодованих висот.

Якщо висота представлена 16 бітами, розмір одного кодованого блоку дорівнює 64 біта, при цьому еквівалентний некодований блок займає 256 біт.

2. Декодування висот. При визначенні висоти для поля ширина якого сягає $w_{b}$ (в блоках), в точці 3 координатами $x$ i $z$ необхідно проводити декодування блоку наступним чином:

1) Визначається номер блоку $n_{b}$, до якого належить точка, в якій необхідно визначити висоту:

$$
n_{b}=x / 4+w_{b} \cdot(z / 4) .
$$

2) Обчислюється номер кодованої висоти $n_{h}$ в блоці:

$$
n_{h}=x \bmod 4+4 \cdot(z \bmod 4) .
$$

3) Відновлюється висота в точці. Для цього обчислюються опорні висоти, що використовувалися для кодування $h_{i}^{c}$ виходячи з виразу (4), знаючи що $h_{\min }=h_{0}^{c}$, а $h_{\max }=h_{3}^{c}$, висоти $h_{0}^{c}$ i $h_{3}^{c}$ можна не відновлювати - вони вже обчислені і записані на початку блоку. За номером вибирається необхідна опорна висота.

Величина похибки, що виникає при кодуванні блоків поля висот може бути розрахована за такою формулою:

$$
e=\frac{1}{S} \cdot \sqrt{\sum_{i=0}^{S-1}\left(h_{i}^{o}-h_{i}^{d}\right)^{2}},
$$

де $S$ - площа поля висот; $h_{i}^{o}, h_{i}^{d}$ - висоти вихідного та відновленого поля висот, відповідно.

3 (5) випливає, що похибка тим більше, чим більший діапазон висот що входять у блок і чим більше нерівномірність розподілу висот всередині блоку. Для досліджених ландшафтів (Україна, Харківська область, частини Харківського та Зміївського районів), середня похибка кодування знаходиться в діапазоні від 0,15 до 0,12\%.

Таким чином, розподіл висот відповідно до виразу (4) у більшості випадків не є оптимальним для кодування, середня величина похибки коду- 
вання досить велика і для ландшафту з діапазоном висот в 100 м становить понад 10 см, а максимальна величина похибки кодування досягає приблизно $120 \mathrm{~cm}$.

3. Аналіз шляхів зменшення похибки кодування блоків висот Якщо використовувати вираз (4), то $з$ найменшою похибкою будуть кодуватися блоки, що містять відносно плавний перепад висот від мінімуму до максимуму.

Лінійний розподіл висот всередині блоку для моделей реальних ландшафтів зустрічається відносно рідко, тому для зменшення похибки доцільно використовувати розподіл опорних висот який кодує блок 3 мінімальною можливою похибкою. Для цього необхідно задавати індивідуальний розподіл (набор зсувів) опорних висот всередині блоку. Для цього в кожному блоці, необхідно зберігати індекс $i$, який адресує вектор зсувів, що було використано при кодуванні блоку. Формат кодованого блоку наведено на рис. 1.

\begin{tabular}{|c|c|c|c|c|c|}
\hline 16 біт & \multicolumn{4}{|c|}{$h_{\min }$} & \multirow{2}{*}{32 біта } \\
\hline 12 біт & \multicolumn{3}{|c|}{$\Delta h$} & $\mathrm{i}$ & \\
\hline \multirow[t]{3}{*}{8 біт } & h0 & hl & $\mathrm{h} 2$ & $\mathrm{~h} 3$ & \multirow{4}{*}{32 біта } \\
\hline & h4 & h5 & h6 & $\mathrm{h} 7$ & \\
\hline & $\mathrm{h} 8$ & h9 & h10 & h11 & \\
\hline 2 біта & h12 & h13 & h14 & h15 & \\
\hline
\end{tabular}

Рис. 1. Індексований блок кодованих висот

Відповідні вектори зберігаються в окремій таблиці, попередньої до опису поля висот. Кожен вектор має розмірність 4 і містить коефіцієнти, яки використовуються для обчислення відповідної опорної висоти.

Як було показано вище, для завдання однієї висоти ландшафту досить використовувати менше ніж 12 біт. Таким чином, зберігаючи мінімальну висоту (12-16 біт) і різницю між максимальною і мінімальною висотою в блоці $\Delta h$ (8-12 біт), а також індекс вектору зсувів, можливо декодувати блок.

Розглянемо процес зменшення розрядності величин $h_{\min }$ i $\Delta h=h_{\max }-h_{\min }$. Для перетворення висоти 3 16-ти бітного подання до 12-ти бітного, використовуємо такі перетворення:

$$
h_{\min }^{\prime}=\left\lfloor h_{\min } / 2^{4}\right\rfloor, \Delta h^{\prime}=\Delta h+\left(h_{\min } \bmod 2^{4}\right),
$$

де \lfloor\rfloor - операція відсікання до найближчого меншого цілого числа.

Такий спосіб мінімізує помилку округлення, що позитивно позначається на величині максимальної похибки кодування.
Значення опорних висот обчислюються таким чином:

$$
h_{j}^{c}=h_{\min }^{\prime}+\Delta h^{\prime} \cdot f_{i}(j),
$$

де $i$ - індекс вектора для інтерполяції, а $j$ - номер опорної висоти; $f_{i}(j)$ - величина коефіцієнта $i$-го вектора для $j$-ої висоти.

При кодуванні блоку відповідно до виразу (7) спочатку здійснюється вибір вектора зсувів який дає найменшу похибку кодування. Далі блок кодується за допомогою обраного вектора і його номер записується у відповідне поле блоку.

4. Синтез набору векторів що використаються для кодування. Для відшукання набору 3 векторів, що дозволяють найкращим чином (з найменшою похибкою) закодувати поле висот необхідно обчислити оптимальний вектор для кожного блоку, після чого вибрати підмножину з $256\left(2^{8}\right)$ векторів, таких щоб похибка кодування була найменшою.

Для визначення оптимального вектора для кодування блоку використовується такий алгоритм:

1. Створюється гістограма розподілу висот всередині блоку.

2. Якщо кількість стовпчиків гістограми менше або дорівнюе 4 (4 - максимальна кількість опорних висот), то найкращими висотами для побудови вектора будуть висоти відповідні до положення цих стовпчиків, і робота алгоритму закінчена.

3. Інакше, визначається два найближчі стовпчика в гістограмі $A$ i $B$, з висотами $H_{A}$ і $H_{B}$ відповідно. Вони замінюються одним стовпчиком $C$, розташованим між ними, висота якого дорівнює

$$
H_{C}=\left(H_{A}+H_{B}\right) / 2 \text {. }
$$

Параметр, що характеризує положення стовпчика $C$, обчислюється таким чином:

$$
X_{C}=X_{A} \cdot \frac{H_{A}}{H_{A}+H_{B}}+X_{B} \cdot \frac{H_{B}}{H_{A}+H_{B}},
$$

де $X_{A}, X_{B}$ - положення стовпчиків $A$ і $B$ на гістограмі.

4. Повторюється крок (2) до тих пір, доки кількість стовпчиків у гістограмі не стане рівн-им чотирьом.

Припустимо, що після роботи алгоритму вийшло 4 стовпчики $D_{0}, D_{1}, D_{2}, D_{3}$ з положенням у гістограмі $X_{0} \leq X \leq X_{2} \leq X_{3}$ відповідно, тоді коефіцієнти вектора $f_{i}(j)$ можна обчислити за формулою:

$$
f_{i}(j)=\frac{\left(X_{j}-h_{\min }\right)}{\Delta h} .
$$

Для вибору множини найкращих 256 векторів, що кодують поле, з мінімальною похибкою, за допомогою методу кластерного аналізу, наприклад методом К-середніх [9]: 
1. Вибирається набір з $K$ довільних, різних векторів вихідної послідовності, які будуть початковими центрами кластерів.

2. Групуються всі вектори вихідної послідовності по обраним на кроці (1) К кластерам, залежно від величини відстані:

$$
d_{i, c}=\frac{1}{4} \cdot \sum_{j=0}^{3}\left|f_{i}(j)-f_{c}(j)\right|,
$$

де $i$ - номер вектора у вихідній послідовності; $c$ номер кластера.

Вектор $i$ належить кластеру $c$, в тому випадку, якщо значення $d_{i, c}$ для даного вектора мінімально можливе.

3. Розраховуються нові центри кластерів, як середнє арифметичне значень $f_{c}(j)$ для всіх векторів які входять до кластеру.

4) Повторюється крок (2) до тих пір, поки вектори не перестануть пересуватися з одного кластера в інший, або кількість таких пересувів не стане менше певної величини.

Для роботи наведеного алгоритму приймемо коефіцієнт К, рівним 256 - максимальній кількості допустимих векторів (якщо індекс кодується 8 бітами). Після закінчення роботи алгоритму, оптимальними векторами будуть центри отриманих кластерів.

За основу для моделювання ландшафту взято ділянку ЛЕП 330 КВ, яка розташована між селами Яковлівка-Костянтівка (Харківська область, Україна) протяжністю $\sim 12$ км. Аналіз гістограми розподілу похибок показав що переважна більшість похибок (більше 90\%) зосереджені в області малих значень. Кількість висот які декодовані $з$ похибкою, яка близька до максимального значення, становить менше ніж 3\%.

Результати обчислення похибок кодування наведені у таблиці 1.

Таблиия 1 - Характер розподілу і величина похибки кодування

\begin{tabular}{|c|c|c|c|c|c|}
\hline \multirow{2}{*}{$\begin{array}{l}\text { № } \\
\text { ПI/ா }\end{array}$} & \multicolumn{4}{|c|}{$\begin{array}{c}\text { \% поля висот, для якого похибка } \\
\text { менша за поріг, см }\end{array}$} & \multirow{2}{*}{$\begin{array}{l}\text { Діапазон } \\
\text { висот, м }\end{array}$} \\
\hline & 1 & 2 & 5 & $>5$ & \\
\hline 1 & 69,67 & 17,84 & 10,81 & 1,68 & 50 \\
\hline 2 & 57,92 & 26,92 & 13,07 & 2,09 & 66 \\
\hline 3 & 64,06 & 22,43 & 11,43 & 2,08 & 65 \\
\hline 4 & 76,95 & 17,37 & 5,05 & 0,63 & 54 \\
\hline 5 & 75,45 & 18,70 & $\overline{5,20}$ & 0,65 & 56 \\
\hline
\end{tabular}

Площа поля висот для якої похибка кодування на якій не перевищує 5 см, становить 97\% поля, при цьому частини поля що кодуються 3 максимальною похибкою розташовані в недоступних або мало доступних частинах ландшафту, розташованих під сильним нахилом до горизонтальної поверхні. Таким чином, використання 256 різних розподілів висот дозволяє зменшити середню похибку більш ніж в 3 рази в порівнянні з лінійним розподілом. Найбільш підходящим для вибору вектора $є$ критерій середньоквадратичної або середньої похибки, які дають найбільшу площу відновленого поля висот 3 похибкою менше ніж 5 см.

5. Оцінка швидкодії декодування поля. Для практичного застосування методу стиснення полів висот та запропонованої СВ ландшафту необхідно оцінити швидкодію функції запиту висоти і величину обчислювальної потужності центрального процесора, яка використається для побудови сітки трикутників, що представляють ландшафт. Оцінка швидкодії функції запиту висоти для різноманітних типів ландшафту наведена в таблиці 2 .

\section{Таблиця 2 - Оцінка швидкодії функції запиту висоти}

\begin{tabular}{|c|c|c|c|c|}
\hline \multirow[b]{2}{*}{$\begin{array}{l}\text { № } \\
\text { ПI/II }\end{array}$} & \multirow[b]{2}{*}{$\begin{array}{c}\text { Характер } \\
\text { ландшафту }\end{array}$} & \multirow{2}{*}{ 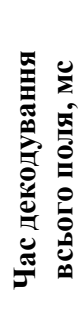 } & \multicolumn{2}{|c|}{$\begin{array}{c}\text { Групові запити } \\
\text { (10 млн.), мс }\end{array}$} \\
\hline & & & 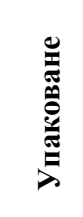 & 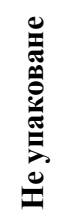 \\
\hline 1 & Поле і яр & 69 & 139 & 102 \\
\hline 2 & Яр та озеро & 64 & 125 & 94 \\
\hline 3 & $\begin{array}{l}\text { Населений пункт і } \\
\text { поле }\end{array}$ & 63 & 112 & 92 \\
\hline 4 & Ліс і поле & 72 & 147 & 104 \\
\hline 5 & Лic & 72 & 165 & 107 \\
\hline
\end{tabular}

Для оцінки використалася ПЕОМ 3 мікропроцесором Intel i5 7500 (ЗГГц). Усі обчислення проводилися за допомогою одного ядра процесора, на ландшафтах розміром 4 кв.км 3 частотою дискретизації по горизонталі 0,5 метра для кодованих та некодованих полів, що містили ідентичні ландшафтні дані (в межах похибки кодування).

Для оцінки швидкодії виконувалось 10 млн. запитів висот які були згруповані наступним чином: обиралося кілька десятків точок, які розташовані на видаленні до 5 метрів від умовного центру запиту, координати якого були отримані випадково, що фактично імітує реальні запити для транспортних засобів та розміщення об'єктів на ландшафті.

Аналіз результатів, наведених у таблиці 2 показує, що запити з кодованого поля здійснюються не більш ніж на 50\% повільніше за некодоване.

\section{Висновки}

1. Обгрунтована необхідність стиснення полів висот для застосування в імітаційно-тренажерних комплексах та ГІС.

2. Запропоновано метод кодування, який дозволяє зменшити об'єм займаного полем висот об’єму ОЗП у 4 рази, що дозволяє або збільшити геометричні розміри поля у горизонтальній площині у 2 рази, або підвищити дискретизацію у 2 рази при незмінному розмірі займаного об’єму ОЗП. 
3. Похибка кодування більш ніж на $98 \%$ площі ландшафту (в середньому рівнинних областей) залишається менше ніж 5 см.

4. Проведена розробка програмного забезпечення та експериментальні дослідження реалізації запропонованого методу. Показано що запропонований метод забезпечує достатню швидкодію функції запиту висот, для роботи імітаційно-тренажерного комплексу та картографічних ГІС у реальному масштабі часу.

\section{СПИСОК ЛІТЕРАТУРИ}

1. Drakopoulos V., Panousopoulos M. Height Field Representation and Compression Using Fractal Interpolation Surfaces. Chaotic Modeling and Simulation. 2012. Volume 4: pp. 593-600.

2. Treib M., Reichl F., Auer S., Westermann R. Interactive Editing of GigaSample Terrain Fields. - EUROGRAPHICS. 2012, Volume 31, Number 2. pp. 383-392. - doi: 10.1111/j.1467-8659.2012.03017.x.

3. Durdevic D., Tartalja, I. HFPac: GPU friendly height field parallel compression. - Geoinformatica. 2013. 17(1), pp. 207-234. doi: 10.1007/s10707-012-0171-x.

4. Lindstrom P, Cohen JD. On-the-fly decompression and rendering of multiresolution terrain. - Proc. of the ACM SIGGRAPH symp. on Interactive 3D Graphics and Games. 2010. Washington, D.C., USA, February 19-21, pp 65-73.

5. Ozsoy A., Swany M. CULZSS: LZSS Lossless Data Compression on CUDA. In Proceedings of the IEEE International Conference on Cluster Computing, 2011.

6. Andrzejewski W., Wremberl R. GPU-WAH: Applying GPUs to Compressing Bitmap Indexes with Word Aligned Hybrid. Database and Expert Systems Applications. Lecture Notes in Computer Science 6262. 2010. pp. 315-329.

7. Simin Y., Zhang J., Gruenwald L. Parallel Spatial Query Processing on GPUs using R-Trees. In Proceedings of BigSpatial, 2013.

8. Качанов П.А. Использование методов кластерного анализа для оптимизации процесса кодирования полей высот / П.А. Качанов, А.А. Зуев - Вісник Національного технічного університету «Харківський політехнічний інституг». Харків: НТУ «ХПІ», 2009. - №23. - С. 85-88.

9. Мандель И.Д. Кластерный аналіз/ И.Д. Мандель. - М.: Финансы и статистика. 1988. -176 с.

Рецензент: д-р техн. наук, проф. О. С. Бутенко, Національний аерокосмічний університет "ХАI”, Київ Received (Надійшла) 23.10.2018 Accepted for publication (Прийнята до друку) 28.11.2018

\section{Разработка метода компактного хранения полей высот в ГИС и имитационно-тренажерных комплексах БПЛА}

А. А. Зуев

Целью статьи является разработка, и исследование метода компактного хранения полей высот описывающих реальные ландшафты, используемые в ГИС и имитационно-тренажерных комплексах. Определены величины необходимой дискретизации поля высот для имитационно-тренажерного комплекса. Рассмотрен метод блочного кодирования и декодирования поля высот, который позволяет обрабатывать как одиночные, так и групповые запросы без полного декодирования поля. Предложена практическая реализация алгоритма построения множества векторов, которые кодируют поле высот с минимальной погрешностью. При проведении исследования путей минимизации ошибки кодирования, использовались методы кластерного анализа. Использование предложенных методов позволяет создать программное обеспечение как для бортового компьютера ГИС БПЛА и наземной станции управления, так и для имитационнотренажерного комплекса используемого для подготовки операторов и предварительного моделирования полетного задания в реальном масштабе времени. Проведен анализ распределения погрешности при кодировании полей, приведено распределение величин погрешности по площади поля для различных типов ландшафтов. Показано быстродействие функции запроса высот для различных типов реальных ландшафтов, модель которых была синтезирована по данным радиолокационного сканирования Земли.

Ключевые слова: ГИС, имитационно-тренажерные комплексы, БПЛА, поля высот, кодирование данных, ландшафты, кластерный анализ.

\section{Development of a compact storage method for height fields in GIS and UAV simulation training complexes}

\section{A. Zuev}

The purpose of the article is development and study of a method of compact storage of height fields representing real landscapes used in GIS and simulation-training complexes. The values of the required height field discretization for the simulationtraining complex are determined. A method of block encoding and decoding of a height field, which allows processing both single and group queries without full decoding of the field, is examined. A practical implementation of the algorithm for constructing a set of vectors that encode a height field with a minimum error is proposed. During the research of ways of minimizing encoding errors, cluster analysis methods were used. Proposed methods enable to create software for both, an onboard computer of a GIS UAV and a ground control station, as well as for a simulation-training complex used for training operators and preliminary modeling of a flight task in real time. The analysis of the error distribution of the height field encoding is conducted; the error distribution of values over the area of the field for various landscape types is given. The performance of the height query function for various types of real landscapes, the model of which was synthesized using radar data of the Earth, is shown.

Keywords: GIS, simulation training complexes, UAV, height fields, data encoding, landscapes, cluster analysis. 